\title{
Triclosan adsorption from model system by mineral sorbent diatomite
}

\author{
Altynay A. Sharipova ${ }^{a, b}, *$, Saule B. Aidarova ${ }^{a}$, Neila Ye. Bekturganova ${ }^{a}$, Aiym Tleuova ${ }^{a, b}$, \\ Moldir Kerimkulova ${ }^{c}$, Orynkul Yessimova ${ }^{c}$, Talmira Kairaliyeva ${ }^{\mathrm{b}}$, Olena Lygina ${ }^{\mathrm{d}}$, \\ Svitlana Lyubchik ${ }^{\mathrm{d}}$, Reinhard Miller ${ }^{\mathrm{b}}$
}

a Kazakh National Research Technical University named after K.I. Satpayev, Almaty, Kazakhstan

${ }^{\mathrm{b}}$ Max-Planck Institute of Colloids and Interfaces, Potsdam, Golm, Germany

${ }^{\mathrm{c}}$ Kazakh national university named after al-Farabi, Kazakhstan

d Universidade Nova de Lisboa, Lisboa, Portugal

\section{G R A P H I C A L A B S T R A C T}

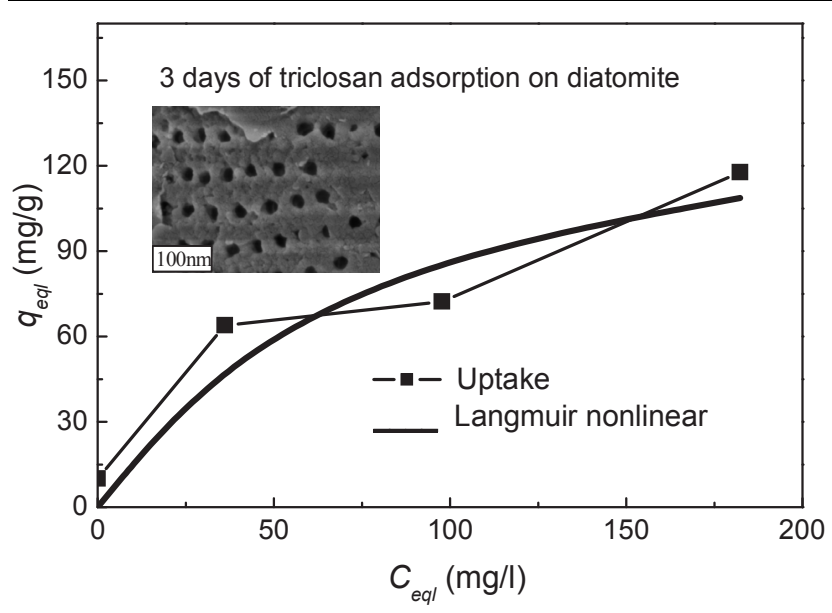

A R T I C L E I N F O

\section{Keywords:}

Triclosan

Adsorption

Diatomite

Sorbents

Adsorption isotherms

\begin{abstract}
A B S T R A C T
Adsorption of model systems of triclosan by mineral sorbent diatomite is studied. The triclosan equilibrium concentration was measured spectrophotometrically, the morphology of the diatomite characterized using scanning electron microscopy and the amount of the adsorbed triclosan on the diatomite quantified by a mass balance. Adsorption isotherms were analyzed according to the linear/nonlinear form of Langmuir, Freundlich, Sips and Toth isotherm models isotherms, using AMPL software. It is shown that nonlinear Langmuir and Sips isotherm model provided suitable fitting results and no pronounced difference in adsorption efficiency between isotherms measured after 1, 2 and 3 days adsorption was observed. Determined maximum adsorption capacity of diatomite towards triclosan $q_{s}$ is $140 \mathrm{mg} / \mathrm{g}$. Averaged calculated values of $\Delta G$ are -9.9 and $-9.6 \mathrm{~kJ} / \mathrm{mol}$ for Langmuir and Sips models respectively. The negative sign of such values indicates spontaneous, physical in nature adsorption.
\end{abstract}

\footnotetext{
* Corresponding author at: Kazakh National Research Technical University named after K.I. Satpayev, Almaty, Kazakhstan.

E-mail addresses: altynay.sharipova@mpikg.mpg.de, a_sharipova85@mail.ru (A.A. Sharipova).
} 
Table 1

Chemical structure of diatomite sorbent.

\begin{tabular}{|c|c|c|c|c|c|c|c|c|}
\hline Sorbent & $\mathrm{SiO}_{2} \%$ & $\mathrm{Al}_{2} \mathrm{O}_{3}$ & $\begin{array}{l}\mathrm{Fe}_{2} \mathrm{O}_{3} \\
\%\end{array}$ & $\begin{array}{l}\mathrm{CaO} \\
\%\end{array}$ & $\begin{array}{l}\mathrm{TiO}_{2} \\
\%\end{array}$ & $\begin{array}{l}\mathrm{MgO} \\
\%\end{array}$ & $\begin{array}{l}\mathrm{Na}_{2} \mathrm{O} \\
\%\end{array}$ & $\begin{array}{l}\mathrm{K}_{2} \mathrm{O} \\
\%\end{array}$ \\
\hline Diatomite & $64-83$ & $0.08-16.3$ & $2-8$ & $0.2-3.5$ & 0.72 & $0.7-1.8$ & $0.3-0.8$ & $0.7-1.0$ \\
\hline
\end{tabular}

\section{Introduction}

Triclosan is a common synthetic antimicrobial agent widely used in domestic and consumer care products such as toothpaste, mouthwash, and soaps [1-22]. Triclosan is additionally used as a stabilizing agent in many cosmetics and detergents [1]. It inhibits bacterial growth by blocking the biosynthesis of lipids [2-4]. Triclosan has also been linked to a number of health and environmental effects, such as irritation of skin, susceptibility to allergies, as well as other environmental toxicities of the aquatic and terrestrial environment $[5,6]$. For example, triclosan has an impact on earthworms (Eisenia fetida) [7] and the Japanese medaka fish [8].

Its widespread use resulted in increased concentrations of triclosan in wastewater treatment plants and sewage water intakes. That is why triclosan biodegradation in the environment and wastewater has recently become an important research topic [1-23]. It was shown that $79 \%$ of triclosan was removed from biological wastewater treatment processes due to the presence of triclosan-degrading bacteria in the activated sludge [9]. A removal of about $90 \%$ was measured in wastewater treatment plants (WWTP) employing a conventional activated sludge process of which $40-60 \%$ was due to biodegradation while the remainder was due to sorption to the sludge $[3,9,10]$.

Nowadays, one of the most promising challenges is the processing of natural raw materials, the utilization of wastes and attraction of ecologically friendly secondary products in economic recycling. At present, different sorbents are used for the treatment of industrial waste water [11-25], including special artificial adsorbents with hierarchical nanostructures [23-25]. Aluminosilicates like diatomite, kaolinite, bentonite and etc. $[13,14,22]$ can be interesting to study as sorbents for waste water treatment due to their folded structure which is reflected in high dispersity, hydrophilicity and good ion exchange properties. Moreover, they are low cost sorbents with excellent sources of raw materials.

Diatomite (SiO2nH2O), or diatomaceous earth, is a soft lightweight rock available in large deposits around the world [22]. This pale colored sedimentary rock consists principally of silica microfossils of aquatic, unicellular alga varying in shape and size of diatom [26]. Diatomite is highly porous, with its structure containing up to $80-90 \%$ voids. It is used in a number of industrial applications, e.g. as filtration medium for various beverages, and inorganic and organic chemicals, and as adsorbent for pet litter and oil spills [27]. Although diatomite has a unique combination of physical and chemical properties its use as an adsorbent in waste water treatment has not been extensively investigated yet $[28,29]$.

In this paper we present results of triclosan adsorption from model systems by the mineral sorbent diatomite. The triclosan equilibrium concentration was measured spectrophotometrically, the morphology of the diatomite was characterized by scanning electron microscopy, and the amount of the triclosan adsorbed on the diatomite was quantified by a mass balance method.

\section{Experiment}

Triclosan (97\%) was purchased from Aldrich. The adsorption process of triclosan was studied in a static mode at the adsorption equilibrium in "triclosan-sorbent" systems. Each adsorption run was performed for a model solution of triclosan at a given $\mathrm{pH}$ in two different batch modes: at varied triclosan concentrations (from 10 to $400 \mathrm{ppm}$ ) and at fixed sorbent loading (at $1 \mathrm{~g} / \mathrm{l}$ ), respectively, aiming at studies of the equilibrium conditions. This process was carried out at constant temperature $\left(24 \pm 1{ }^{\circ} \mathrm{C}\right)$. At the end of the experiments, the adsorbent was removed by filtration through membrane filters with a pore size of $0.45 \mu \mathrm{m}$. The triclosan equilibrium concentration was measured spectrophotometrically with a Cary 50 Cons at a fixed wavelength of $280 \mathrm{~nm}[30,31]$.

The experiments on triclosan adsorption were performed from ethanol solutions instead of standard aqueous solutions [32,33]. Such step allows a large increase in the concentration of the adsorbate in solution due to its $100 \%$ solubility in ethanol, and hence it was possible to fully explore the adsorption capacity of diatomite towards triclosan.

As a sorbent, we used the mineral diatomite produced in the Aktobe deposit of West Kazakhstan. Low temperature Nitrogen adsorption analyzed by the BET method was used to characterize diatomite.

The chemical structure and characteristics of the diatomite is given in Tables 1 and 2. As it is shown the basic components of diatomite are silicium dioxide $\mathrm{SiO}_{2}(60-70 \%)$ and aluminium oxide (9\%) with specific surface area equaled to $32 \mathrm{~m}^{2} / \mathrm{g}$.

The structure of the sorbent was studied using cryo-scanning electron microscopy, SEM (Zeiss Gemini LEO 1550). For the characterization, a droplet of the aqueous particle suspension was placed on a sample holder and left to dry at atmospheric pressure and room temperature and followed by sputtering with a gold/palladium mixture to avoid electron charging of the samples during SEM analysis. The samples were studied using an operating voltage of $3 \mathrm{kV}$ and different magnification.

The amount of the adsorbed triclosan on the diatomite was quantified by a mass balance method. The adsorption capacity of the sorbent $\left(q_{\text {eql }}\right)$ can be expressed in terms of the triclosan amount adsorbed per unit of sorbent mass, i.e. the uptake $(\mathrm{mg} / \mathrm{g})$ is given by:

$q_{e q l}=\frac{\left(C_{i n i t}-C_{e q l}\right)}{m}$

The sorption efficiency of the system (Rem\%) indicated by the percentage of removed triclosan relative to the initial amount, i.e. Rem in $\%$ is given by

$\operatorname{Rem} \%=\frac{\left(C_{\text {init }}-C_{\text {eql }}\right)}{C_{\text {init }}} \times 100$

where $C_{i n i t}$ and $C_{e q l}$ are, respectively, the initial and equilibrium concentrations of triclosan in solution $(\mathrm{mg} / \mathrm{l})$ and $\mathrm{m}$ is the sorbent dosage $(\mathrm{g} / \mathrm{l})$.

Fitting the experimental adsorption data was performed by several well-known isotherm models.

\subsection{Langmuir isotherm}

This model assumes monolayer coverage and constant binding energy between surface and adsorbate [34]:

Table 2

Characteristics of diatomite.

\begin{tabular}{llll}
\hline Sorbent & Density, $\rho, \mathrm{cm}^{3} / \mathrm{g}$ & Specific surface area, $\mathrm{m}^{2} / \mathrm{g}$ & Sizes of pores, nm \\
\hline Diatomite & $2.17-2.26$ & 32 & 3.8 \\
\hline
\end{tabular}



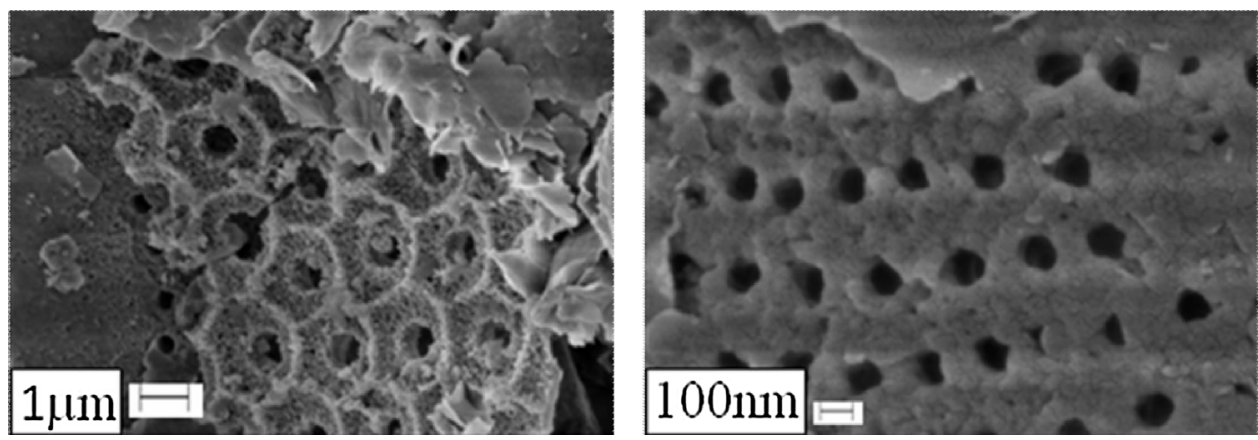

Fig. 1. SEM-images of sorbent diatomite. $q_{e q l}=q_{\max } \frac{K_{L} C_{e q l}}{1+K_{L} C_{e q l}}$

where $q_{\text {max }}$ is the maximum adsorption capacity (monolayer coverage), i.e. mmol of the adsorbate per $(\mathrm{g})$ of adsorbent; $K_{L}$ is the constant of the Langmuir isotherm if the enthalpy of adsorption is independent of coverage.

In order to calculate the main parameters of the Langmuir isotherm model a linearized form of the equation is required.

The linearized Langmuir model (a plot of $1 / q_{\text {eql }}$ vs. $1 / C_{e q l}$ ) is expected to give a straight line with the intercept of $1 / q_{\max }$ :

$\frac{1}{q_{e q l}}=\frac{1}{K_{L} q_{\max }} \frac{1}{C_{e q l}}+\frac{1}{q_{\max }}$

\subsection{Freundlich isotherm}

For the special case of a surface with heterogeneous energies in which the energy term $\left(K_{F}\right)$ varies as a function of surface coverage, the Freundlich model can be used [35]:

$q_{e q l}=K_{F} \times C_{e q l}^{1 / n_{F}}$

where $K_{\mathrm{F}}$ is equilibrium constant of the Freundlich equation, related to the adsorption capacity, and $1 / n_{F}$ is a parameter related to the strength of the adsorbent - adsorbate interaction, thus associated with the adsorption efficiency.

Similarly, to the linearized Langmuir model also the Freundlich isotherm can be modified in order to calculate main parameters.

For the linearization of the Freundlich isotherm, the log-log version is used:

$\log q_{e q l}=\log K_{\mathrm{F}}+1 / n_{F} \log C_{e q l}$

However, when only a subset of the adsorption data is correlated for later use in a specific adsorption application, without the need for extrapolation to other adsorbates or to a substantially different temperature range, it is more appropriate to obtain a less general but more accurate representation of the adsorption equilibria. The Sips and Toth isotherm models [37] can be used then for that purpose. We used the nonlinear Sips (Freundlich-Langmuir) isotherm model [36] in order to obtain a more accurate representation of the adsorption equilibrium parameters:

$q_{e q l}=\frac{q_{s}\left(K_{s} C_{e q l}\right)^{1 / n}}{1+\left(K_{s} C_{e q l}\right)^{1 / n}}$

where $q_{s}$ is the adsorption capacity of the adsorbent, $K_{s}$ is the equilibrium constant and $n$ is the index of heterogeneity. The parameter $n$ characterizes the interaction between adsorbate and adsorbent, and its magnitude increases with the heterogeneity of the system. It should be noted that for $n=1$ Eq. (3) becomes a Langmuir type equation. Alternatively, for either $C_{e q l}$ or $K_{s}$ approaching 0 , this isotherm reduces to the well-known Freundlich isotherm [35].

The Toth isotherm is an empirical model that was developed to yield an improved fit versus traditional Langmuir isotherm modelling. It is often useful for describing heterogeneous systems. The Toth isotherm model approaches the Henry region at infinite dilution [34]:

$q_{e q l}=q_{\max } \frac{K_{T} C_{e q l}}{\left[1+\left(K_{T} C_{e q l}\right)^{n_{T}}\right]^{1 / n_{T}}}$

The triclosan concentrations in waste water were measured by UV-vis spectrophotometer Cary 50 Cons and determined from a calibration curve of pure triclosan in ethanol solution at a fixed wavelength of $280 \mathrm{~nm}[30,31]$.

\section{Results and discussion}

Fig. 1 represent the SEM image of diatomite. As it can be seen in Fig. 2 the size of the sorbent is approximately $100 \mathrm{~nm}$ and has slit pores, with a specific surface area of $32 \mathrm{~m}^{2} / \mathrm{g}$ (Table 1 ).

The adsorption measurements of triclosan on diatomite was perform at fixed loading $(1 \mathrm{~g} / \mathrm{l})$ of adsorbent aimed at determining the equilibrium conditions of the adsorption process (Figs. 2-3).

As can be seen in Fig. 2 the adsorption efficiency (Rem \%) decreases with increasing triclosan concentration at a constant diatomite loading, which is consistent with the theory (see Eq. (2)). However, no pronounced difference in adsorption efficiency between the isotherms measured after 1-3 days of equilibration is observed (Fig. 2).

The experimental isotherms presented in Fig. 3 again show no significant differences between day 1-3. Such behavior reveals that the system got into equilibrium conditions after a time less than 1 day of adsorption. All measured adsorption isotherm show a maximum adsorption capacity value of ca. $120 \mathrm{mg} / \mathrm{g}$.

The adsorption isotherms were analyzed by fitting the experimental data using linear and nonlinear Langmuir, Freundlich, Sips and Toth isotherm models. The least squares algorithm was employed to fit the experimental isotherm by a nonlinear approach using the AMPL

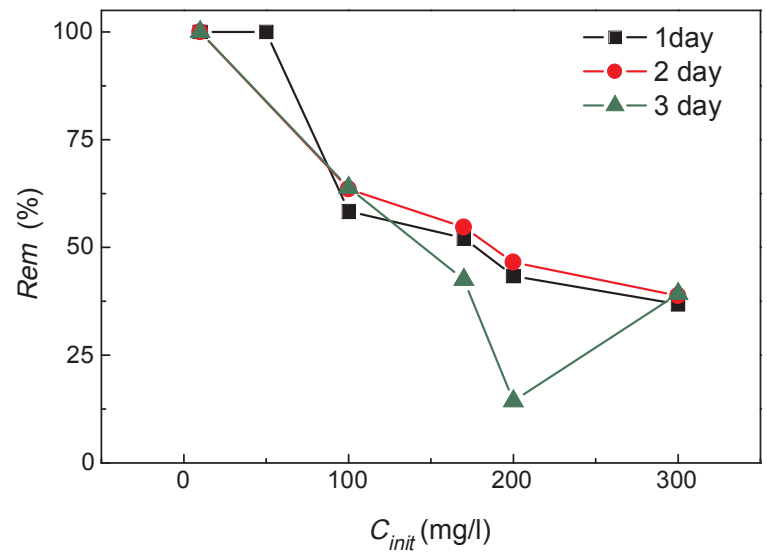

Fig. 2. Adsorption efficiency (Rem \%) of triclosan on diatomite at fixed adsorbent loading ( $1 \mathrm{~g} / \mathrm{l}$ ) after 1 (squares), 2 (circles) and 3 (triangles) days. The lines are drawn as guide to the eyes. 


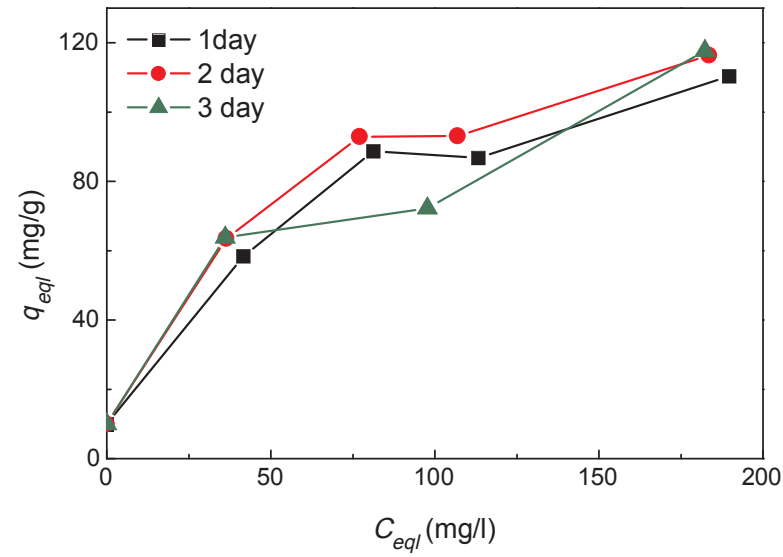

Fig. 3. Experimental adsorption isotherms as a function of triclosan concentration measured after 1 (squares), 2 (circles) and 3 (triangles) days of adsorption. The lines are drawn as guide to the eyes.

programming language. This method does not transform data sets and hence, no distortions are created in the original error distribution. The results of fitting are presented in Fig. 4 and Table 3.

As can be seen Freundlich (linearized/nonlinearized) and Toth isotherm models did not adequately describe the resulting adsorption curves due to its complex behavior in the investigated concentration range, which has been previously reported elsewhere [36].

However, the two-parameter Langmuir linearized/nonlinearized and the three-parameter Sips isotherm models fit adequately the experimental results (Fig. 4). The maximum adsorption capacities obtained by the non-linearized form of the Langmuir and Sips models are identical ( $q_{s} \sim 140 \mathrm{mg} / \mathrm{g}$.), while $q_{s}$ obtained by the linearized Langmuir model slightly decrease from 142 to $139 \mathrm{mg} / \mathrm{g}$ from day 1 to day 2 and goes to $113 \mathrm{mg} / \mathrm{g}$ at day 3 (Table 3). Thus, for the following discussion were chose the results of the fitting obtained by the nonlinearized Langmuir and Sips models. Moreover, it should be noted that the calculated parameter $n$ in Sips model is equal to 1, hence converting Sips to the simpler Langmuir equation. Thus, the triclosan and diatomite interact trough physical forces, namely electrostatic. The equilibrium model parameter $b$ and $K_{S}$ vary between $0.016-0.023$ depending on the applied model and equilibration time (Table 3 ). Nevertheless, such variation can be considered as not significant.

In order to understand more deeply the equilibration of the investigated systems the Gibbs free energy was calculated for the isotherms measured after 1, 2 and 3 days of adsorption. For this purpose, the equilibrium constants ( $b$ and $K_{s}$ ) obtained by Langmuir and Sips models were used in the calculations. The change in the standard Gibbs free energy $\Delta G$ was calculated from the Van't-Hoff equation:

$\Delta G=-R T \ln (K)$

where $K$ is the apparent equilibrium constant; $T$ is the temperature in Kelvin and $R$ is the gas constant $(8.314 \mathrm{~J} / \mathrm{mol} \mathrm{K})$. As can be seen in Table 3 all $\Delta G$ values are negative which indicates that the nature of the adsorption process is spontaneous which confirms our previous findings [38].

Also, the observed slight variations of the $\Delta G$ values (from -9.953 to $-10.245 \mathrm{~kJ} / \mathrm{mol}$ for the Langmuir model and from -9.346 to $-9.953 \mathrm{~kJ} / \mathrm{mol}$ for the Sips model) indicate that with increasing adsorbent/adsorbate contact time the adsorption is more equilibrated. Nevertheless, we can conclude that in the studied adsorption time frame of 1 day the equilibration is sufficiently established.

\section{Conclusion}

The triclosan adsorption by the local mineral sorbent diatomite is studied where the triclosan equilibrium concentration was measured
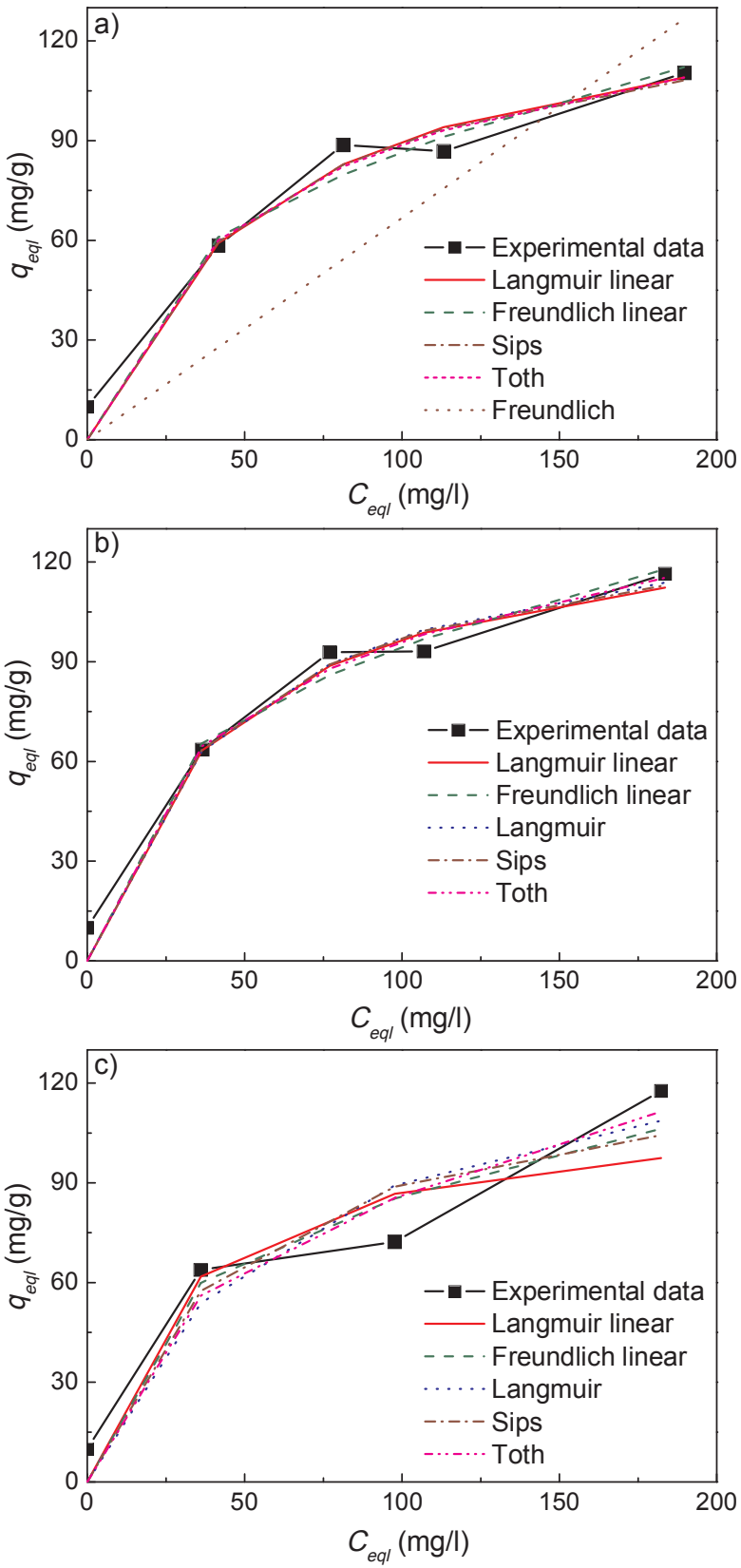

Fig. 4. Experimental adsorption isotherms measured after: a) 1 day of adsorption (squares), b) 2 days of adsorption (circles); c) 3 days of adsorption (triangles); the solid lines correspond to the fitted Langmuir linear model; the dashed lines correspond to the Freundlich fitting model; the dot line correspond to the nonlinear Langmuir model; the dash-dotted line correspond to the Sips model fitting; the dash-dot-dot line correspond to the fitted Toth model of the experimental adsorption data; the short dashed line correspond to the nonlinear Freundlich fitting.

spectrophotometrically, the morphology of the diatomite are characterized by scanning electron microscopy, and the amount of the adsorbed triclosan on the diatomite surface was quantified by a mass balance method.

The linearized/nonlinearized form of the Langmuir, Freundlich and Sips, and Toth isotherm models, are used for fitting the experimental adsorption isotherms. It is shown that the nonlinearized Langmuir and Sips isotherm models provide suitable fitting results and no pronounced differences in the adsorption efficiency between the isotherms measured after 1, 2 and 3 days adsorption was observed. The determined maximum adsorption capacity of diatomite towards triclosan $q_{s}$ is $140 \mathrm{mg} / \mathrm{g}$. The averaged calculated values of $\Delta G$ amount to -9.9 and $-9.6 \mathrm{~kJ} / \mathrm{mol}$ for the Langmuir and Sips models, respectively. The 
Table 3

Isotherm constant of two and three-parameter models for triclosan adsorption onto diatomite sorbent.

\begin{tabular}{lllll}
\hline Isotherm model & Constant & 1 day & 2 days & 3 days \\
\hline \multirow{2}{*}{ Langmuir } & $q_{s}(\mathrm{mg} / \mathrm{g})$ & 141.0 & 142.0 & 145.2 \\
& $b(\mathrm{l} / \mathrm{g})$ & 0.018 & 0.022 & 0.016 \\
& $\Delta G(\mathrm{~kJ} / \mathrm{mol})$ & -9.953 & -9.456 & -10.245 \\
Langmuir (linearized form) & $q_{s}(\mathrm{mg} / \mathrm{g})$ & 142.9 & 138.9 & 113.6 \\
& $b_{l}(\mathrm{l} / \mathrm{g})$ & 0.017 & 0.023 & 0.033 \\
Sips & $q_{s}(\mathrm{mg} / \mathrm{g})$ & 140 & 140 & 131 \\
& $K_{s}(\mathrm{l} / \mathrm{g})$ & 0.018 & 0.023 & 0.022 \\
& $n_{s}$ & 1 & 1 & 1 \\
& $\Delta G(\mathrm{~kJ} / \mathrm{mol})$ & -9.953 & -9.346 & -9.456 \\
Toth & $q_{s}(\mathrm{mg} / \mathrm{g})$ & 107.6 & 76.3 & 0.03 \\
& $K_{T}(\mathrm{l} / \mathrm{g})$ & 0.025 & 0.053 & 4364 \\
& $n_{T}$ & 0.91 & 0.84 & 0.58 \\
Freundlich (linearized form $)$ & $K_{F}(\mathrm{l} / \mathrm{g})$ & 13.6 & 17.7 & 16.8 \\
& $n_{F}$ & 2.49 & 2.75 & 2.82 \\
& & & &
\end{tabular}

negative sign of the values indicates a spontaneous adsorption.

\section{Acknowledgments}

The work was financially supported by a project 1439GF4 of the Ministry of Education and Science of the Republic of Kazakhstan, and the EU Training Network CoWet.

\section{References}

[1] M. Adolfsson-Erici, M. Pettersson, J. Parkkonen, J. Sturve, Triclosan, a commonly used bactericide found in human milk and in the aquatic environment in Sweden, Chemosphere 46 (2002) 1485-1489.

[2] H.P. Schweizer, Triclosan: a widely used biocide and its link to antibiotics, FEMS Microbiol. Lett. 202 (2001) 1-7.

[3] M. Braoudaki, A.C. Hilton, Low level of cross-resistance between triclosan and antibiotics in Escherichia coli K-12 and E. coli 055 compared to E-coli O157, FEMS Microbiol. Lett. 235 (2004) 305-309.

[4] D.E. Latch, J.L. Packer, B.L. Stender, J. Van Overbeke, W.A. Arnold, K. McNeill, Aqueous photochemistry of triclosan: formation of 2,4-dichlorophenol, 2,8-dichlorodibenzo-p-dioxin, and oligomerization products, Environ. Toxicol. Chem. 24 (2005) 517-525.

[5] D. Sabaliunas, S.F. Webb, A. Hauk, M. Jacob, W.S. Eckhoff, Environmental fate of triclosan in the River Aire basin, UK, Water Res. 37 (2003) 3145-3154.

[6] M.A. Coogan, R.E. Edziyie, T.W. La Point, B.J. Venables, Algalbioaccumulation of triclocarbantriclosan, and methyl-triclosan in a North Texas wastewater treatment plant receiving stream, Chemosphere 67 (2007) 1911-1918.

[7] D. Lin, Q. Zhou, X. Xie, Y. Liu, Potential biochemical and genetic toxicity of triclosan as an emerging pollutant on earthworms (Eisenia fetida), Chemosphere 81 (2010) 1328-1333.

[8] M. Nassef, S. Matsumoto, M. Seki, F. Khalil, I.J. Kang, Y. Shimasaki, Y.T. Honjo, Acute effects of triclosan, diclofenac and carbamazepine on feeding performance of Japanese medaka fish (Oryzias latipes), Chemosphere 80 (2010) 1095-1100.

[9] H. Singer, S. Muller, C. Tixier, L. Pillonel, Triclosan: occurrence and fate of a widely used biocide in the aquatic environment: field measurements in wastewater treatment plants, surface waters, and lake sediments, Environ. Sci. Technol. 36 (2002) 4998-5004.

[10] K. Bester, Triclosan in a sewage treatment process-balances and monitoring data, Water Res. 37 (2003) 891-3896.

[11] J. Heidler, R.U. Halden, Mass balance assessment of triclosan removal during conventional sewage treatment, Chemosphere 66 (2007) 362-369.
[12] S.D. Khattri, M.K. Singh, Colour removal from synthetic dye wastewater using a bioadsorbent, water, Air Soil Pollut. 120 (2000) 283-294.

[13] V.K. Gupta, P.J.M. Carrott, M.R. Carrott, T.L. Suhas, Low-cost adsorbents: growing approach to wastewater treatment-a review, Crit. Rev. Environ. Sci. Technol. 39 (2009) 783-842.

[14] Z. Bekçi, Y. Seki, M.K. Yurdakoç, Equilibrium studies for trimethoprim adsorption on montmorillonite KSF, J. Hazard. Mater. B 133 (2006) 233-242.

[15] M.D. Ahmaruzzaman, Adsorption of phenolic compounds on low-cost adsorbents: a review, Adv. Colloid Interface Sci. 143 (2008) 48-67.

[16] A. Bhatnagar, A.K. Jain, A comparative adsorption study with different industrial wastes as adsorbents for the removal of cationic dyes from water, J. Colloid Interface Sci. 281 (2005) 49-55.

[17] E.K. Putra, R. Pranowo, J. Sunarso, N. Indraswati, S. Ismadji, Performance of activated carbon and bentonite for adsorption of amoxicillin from wastewater: mechanisms isotherms and kinetics, Water Res. 43 (2009) 2419-2430.

[18] Y. Yoon, P. Westerhoff, S.A. Snyder, Adsorption of 3H-labeled 17-bestradiol on powdered activated carbon, Water. Air. Soil Pollut. 166 (2005) 343-351.

[19] S.A. Snyder, S. Adham, A.M. Redding, F.S. Cannon, J. DeCarolis, J. Oppenheimer, E.C. Wert, Y. Yoon, Role of membranes and activated carbon in the removal of endocrine disruptors and pharmaceuticals, Desalination 202 (2007) 156-181.

[20] S. Babel, T.A. Kurniawan, Low-cost adsorbents for heavy metals uptake from contaminated water: a review, J. Hazard. Mater. 97 (2003) 219-243.

[21] A.A. Sharipova, S.B. Aidarova, N.E. Bekturganova, A. Tleuova, O. Lygina, S. Lyubchik, R. Miller, Adsorption of model system of triclosan by sorbents obtained from wastes of production, Coll. Surf. A 505 (2016) 193-196.

[22] M.A.M. Khraisheh, Y.S. Al-degs, W.A.M. Mcminn, Remediation of wastewater containing heavy metals using raw and modified diatomite, Chem. Eng. J. 99 (2004) 177-184.

[23] J. Fei, Y. Cui, X. Yan, W. Qi, Y. Yang, K. Wang, Q. He, J. Li, Controlled preparation of $\mathrm{MnO} 2$ hierarchical hollow nanostructures and their application in water treat ment, Adv. Mater. 20 (2008) 452-456.

[24] L. Zhong, J. Hu, H. Liang, A. Cao, W. Song, L. Wan, Self-Assembled 3D flowerlike iron oxide nanostructures and their application in water treatment, Adv. Mater. 18 (2006) 2426-2431.

[25] J. Fei, J. Li, Controlled preparation of porous TiO2-Ag nanostructures through supramolecular assembly for plasmon-enhanced photocatalysis, Adv. Mater. 27 (2015) 314-319.

[26] J.F. Lemonas, Diatomite, Am. Ceram. Soc. Bull. 6 (1997) 92.

[27] Y.S. Al-Degs, M.F. Tutunji, R.A. Shawabkeh, The feasibility of using diatomite and Mn diatomite for remediation of $\mathrm{Pb} 2+, \mathrm{Cu} 2+$, and $\mathrm{Cd} 2+$ from water, Sep. Sci. Technol. 35 (2000) 2299-2310.

[28] S. Aytas, S. Akyil, M.A.A. Aslani, U. Aytekin, Removal of uranium from aqueous solution by diatomite (Kieselguhr), J. Radioanal. Nucl. Chem. 240 (1999) 973-976.

[29] P.B. Michell, K. Atkinson, The novel use of ion exchange material as an aid to reclaiming derelict mining land, Miner. Eng. 4 (1991) 1091.

[30] J.C. Carlson, M.I. Stefan, J.M. Parnis, Ch. D. Metcalfe, Direct UV photolysis of selected pharmaceuticals, personal care products and endocrine disruptors in aqueous solution, Water Res. 84 (2015) 350-361.

[31] R. Lavecchia, A. Zuorro, Experimental study of the inclusion of triclosan in hydroxy propyl- $\beta$-cyclodextrin, Chem. Eng. Trans. 17 (2009) 1083-1088.

[32] L. Sanchez-Prado, R. Barro, C. Garcia-Jares, M. Llompart, M. Lores, Ch. Petrakis, N. Kalogerakis, D. Mantzavinos, E. Psillakis, Sonochemical degradation of triclosan in water and wastewater, Ultrason. Sonochem. 15 (2008) 689-694.

[33] B. Wilson, R.F. Chen, M. Cantwell, A. Gontz, J. Zhu, C.R. Olsen, The partitioning of triclosan between aqueous and particulate bound phases in the Hudson River Estuary, Mar. Pollut. Bull. 59 (2009) 207-212.

[34] I. Langmuir, The constitution and fundamental properties of solids and liquids, J. Am. Chem. Soc. 38 (1916) 2221

[35] H.M.F. Freundlich, Over the adsorption in solution, J. Phys. Chem. 57 (1906) 385.

[36] R. Sips, On the structure of a catalyst surface, J. Chem. Phys. 16 (1948) 490-495.

[37] J. Toth, State equations of the solid gas interface layer, Acta Chem. Acad. Hung. 69 (1971) 311-317.

[38] S.B. Lyubchik, A.I. Lyubchik, O.S. Lygina, S.I. Lyubchik, I.M. Fonseca, Comparison of the Thermodynamic Parameters Estimation for the Adsorption Process of the Metals from Liquid Phase on Activated Carbons. in: J.C. Moreno-Piraján (Ed.), Book Thermodynamics - Interaction Studies - Solids, Liquids and Gases (2011) 95-122 ISBN: 978-953-307-563-1, Chapter N 4. 